\title{
Fulvestrant 500 milligrams as endocrine therapy for endocrine sensitive advanced breast cancer patients in the real world: the Ful500 prospective observational trial
}

\author{
Luca Moscetti ${ }^{1,8}$, Maria Agnese Fabbri ${ }^{1}$, Clara Natoli ${ }^{2}$, Patrizia Vici, Teresa \\ Gamucci ${ }^{4}$, Isabella Sperduti ${ }^{5}$, Laura Iezzi ${ }^{6}$, Elena Iattoni ${ }^{8}$, Laura Pizzuti ${ }^{3}$, Carmine \\ Roma7, Angela Vaccaro ${ }^{4}$, Giuliana D'Auria ${ }^{1}$, Mariella Mauri ${ }^{7}$, Lucia Mentuccia ${ }^{4}$, \\ Antonino Grassadonia ${ }^{2}$, Maddalena Barba $^{3}$ and Enzo Maria Ruggeri ${ }^{1}$ \\ ${ }^{1}$ Division of Medical Oncology, AUSL Viterbo, Belcolle Hospital Strada Sammartinese, 01100 Viterbo, Italy \\ ${ }^{2}$ Department of Medical, Oral and Biotechnological Sciences and CeSI-MeT University G. D'Annunzio, Chieti-Pescara, 66100 \\ Chieti, Italy \\ ${ }^{3}$ Division of Medical Oncology 2, Regina Elena National Cancer Institute, 00144 Roma, Italy \\ ${ }^{4}$ Medical Oncology Unit, ASL Frosinone, 03100 Frosinone, Italy \\ ${ }^{5}$ Biostatistics Unit, Istituto Regina Elena, 00144 Rome, Italy \\ ${ }^{6}$ Medical Oncology Unit, SS. Annunziata Hospital, 66100 Chieti, Italy \\ ${ }^{7}$ Division of Oncology, Azienda Ospedaliera San Giovanni Addolorata, 00184 Rome, Italy \\ ${ }^{8}$ Department of Oncology and Haematology, Azienda Ospedaliero Universitaria Policlinico di Modena, 41124 Modena, Italy \\ Correspondence to: Luca Moscetti, email: moscetti.luca@policlinico.mo.it \\ Keywords: fulvestrant, metastatic breast cancer, endocrine therapy, endocrine resistance \\ Received: October 11, $2016 \quad$ Accepted: March 04, 2017 Published: April 20, 2017 \\ Copyright: Moscetti et al. This is an open-access article distributed under the terms of the Creative Commons Attribution License \\ 3.0 (CC BY 3.0), which permits unrestricted use, distribution, and reproduction in any medium, provided the original author and \\ source are credited.
}

\section{ABSTRACT}

The observational prospective trial herein presented aimed at evaluating the efficacy of fulvestrant $500 \mathrm{mg}$ in the treatment of endocrine sensitive advanced breast cancer patients from the real world setting. The primary end point was clinical benefit rate (CBR). Secondary end points were overall survival (OS), progression free survival (PFS) and tolerability. One hundred sixty three patients were enrolled. At a median follow up of 20 months, the $61 \%$ of patients reached CBR, whose median duration was $\mathbf{1 0 . 8}$ months. Median PFS and OS were 7 and 35 months, respectively. Endocrine sensitive patients showed better PFS and OS. No relevant toxicity appeared when analyzing safety data. In multivariate analysis, visceral involvement, endocrine sensitivity and previous endocrine therapy were prognostic factor for PFS, whereas endocrine sensitivity and metastasis at diagnosis had prognostic relevance for OS. Estrogen receptor expression $\mathbf{7 5 0} \%$, single metastatic site, and no prior endocrine therapy for advanced disease were predictive of CBR. In this prospective trial, fulvestrant $\mathbf{5 0 0} \mathbf{~ m g}$ appeared to be a safe and active treatment and confirmed its efficacy in the daily clinical practice. A high percent expression of estrogen receptors (above $50 \%$ ) was associated with higher CBR. Treatment was very well tolerated. Endocrine sensitivity had a major impact on treatment outcome. As expected, patients who had received first-line endocrine therapy for advanced disease exhibited worse outcome and a lower CBR.

\section{INTRODUCTION}

Breast cancer is the most common cancer in women and its incidence rises in postmenopause [1]. In postmenopausal women, hormonal-receptor positive breast cancer is the most frequent subtype. Notwithstanding the increasingly common diagnosis at an early stage and the goals achieved in the adjuvant setting, about one third of 
these patients is expected to relapse [2, 3]. Endocrine therapy is the mainstay of treatment in hormone receptor positive HER2 negative postmenopausal advanced-breast cancer patients. The therapeutic armamentarium has greatly enlarged and currently includes a notable number of drugs, mainly, but not exclusively, represented by the selective estrogen receptor modulators (SERM), steroidal and non-steroidal aromatase inhibitors (AIs) and selective ER down-regulators (SERD) [4]. In first line, the use of AIs was associated with higher response rates and longer time to treatment progression compared to tamoxifen [5-7]; unfortunately, most of the patients will experience disease progression while on or after AIs, thus requiring further therapeutic options. Fulvestrant is a $7 \alpha$-alkylsulfinyl analog of 17ß-estradiol that works as a competitive estrogen receptor (ER) antagonist but, differently from tamoxifen, it shows no agonist activity [8]. Throughout binding to its ligand, fulvestrant induces the rapid degradation of the ER and leads to the reduction of its intracellular levels; moreover, ER not only lacks of intrinsic estrogen-agonist effects, but also induces a down-regulation of the progesterone receptor (PgR), thus blocking the proliferative signaling from hormonal-activated pathways [9]. The clinical effectiveness of fulvestrant in post-menopausal advanced-breast cancer women previously treated with endocrine therapies has been largely studied. Fulvestrant proved efficacy at $250 \mathrm{mg}$ both in the second and first-line settings [10,11, 12, 13, 14, 15]. In a phase II neoadjuvant trial, fulvestrant, at the high- dose (HD) of $500 \mathrm{mg}$ was associated with an increased biological activity compared to the dose of $250 \mathrm{mg}$, resulting in greater reductions of ER expression and inhibition ofof cell growth $[16,17,18]$. On this basis, a double-blinded, randomized, phase III study (CONFIRM) compared the two doses of fulvestrant and showed the superiority of the high dose [19, 20]. Confirmative evidence on the efficacy of fulvestrant 500 has come from other trials [21, 22, 23, 24]. Moreover, the FIRST trial has compared the activity of HD fulvestrant to Anastrozole as fist-line treatment for naïve hormone receptor-positive metastatic breast cancer patients. The study showed higher efficacy of fulvestrant [25, 26], which was further confirmed by a phase III randomized clinical trial of fulvestrant $500 \mathrm{mg}$ compared to Anastrozole as firstline hormonal treatment in patients with hormone-receptor positive metastatic breast cancer [27]. Since most of the patients enrolled in randomized clinical trials are selected, we performed a multicenter observational prospective trial to evaluate the efficacy of fulvestrant in advanced breast cancer patients treated in routine practice.

\section{RESULTS}

One hundred and sixty-three (N:163) consecutive eligible patients from 2010 to 2015 were enrolled at four Italian oncologic centers. Main patients' characteristics were reported in Table 1: median age was 68 years (range 35-87), ECOG PS was $0 / 1$ in $95 \%$ of patients, adjuvant ET was administered in $75 \%$ of patients, $55 \%$ of them had received first-line ET (11 tamoxifen, 78 AIs), 30\% had bone-only disease, $44 \%$ visceral disease, $52 \%$ had more than one site of disease, the expression of estrogen receptor/progesterone receptors was $>50 \%$ in $78 / 50 \%$. The majority (98.8\%) of these patients received treatment as planned without delays or drug omission; $67 \%$ of patients received further therapy after fulvestrant. Safety analysis did not show relevant toxicity, no grade 3 or 4 toxicities were reported and no serious adverse events were observed (Table 2). All the events were manageable and main toxicities were: pain in the injection sites, asthenia, and arthralgia. Overall, CBR was reached in $61 \%$ of patients (95\%CI 51-66), with a median duration of 10.8 months (CI95\% 8.2-13.4). At a median follow up of 20 months (mo), median PFS was 7 months (95\% CI 6-8), and median OS was 35 months (95\%CI 26-52) (Figure 1A and 1B). Endocrine sensitive (ES) patients had better PFS and OS compared to non-endocrine sensitive women (non-ES). Median PFS was 8 (95\% CI 5-8) months in ES vs 6 months (CI 95\% 6-10) in non-ES ( $\mathrm{p}=0.05$ ), and median OS was 52 months (95CI\% 23-81) in ES vs 25 months (95\% CI 1535 ) in non- $\mathrm{ES}(\mathrm{p}=0.05)$ (Figure $2 \mathrm{~A}$ and $2 \mathrm{~B})$. In multivariate analysis, visceral involvement, endocrine sensitivity and previous ET were prognostic factors for PFS, whereas endocrine sensitivity and metastasis at diagnosis were prognostic factors for OS. Estrogen receptor expression $>50 \%$, no more than 1 site of metastasis and no previous ET for advanced disease were predictive of CBR (Table 3).

\section{DISCUSSION}

Fulvestrant represents an ET option for endocrine sensitive breast cancer in the post-menopausal setting. The strength of this drug is strictly related to the high compliance ensured by the intramuscular injection that allows its regular administration. This avoids the uncertainty of assumption which may affect the efficacy of any orally administered drug. The low incidence of adverse events further encourages fulvestrant use. The dose of fulvestrant used in our population $(500 \mathrm{mg}$ ) was superior to the $250 \mathrm{mg}$ used in the early trials comparing fulvestrant to AIs and tamoxifen, and represents the currently approved dose. Recently, a network meta-analysis has showed the efficacy of $500 \mathrm{mg}$ fulvestrant in terms of OS over the $250 \mathrm{mg}$ dose and megestrole acetate [28]. Although clinical trials provide high quality data about the efficacy and safety of drugs, additional details from the "outside trial" setting could help physicians in the daily practice. Consistent evidence in support of fulvestrant safety and efficacy in the clinical practice have come from recent studies. In the retrospective trial from Ishida and coauthors, 117 patients were treated with HD fulvestrant. In this cohort, CBR was $42 \%$ and median time to progression (TTP) was 6 months; previous endocrine sensitivity and absence of liver metastasis correlated with TTP [29]. In our prospective trial, we evaluated the efficacy of fulvestrant in the clinical daily practice. Our results from 
Table 1: Characteristics of patients

\begin{tabular}{|c|c|c|}
\hline Number of patients & $n=163$ & $\%$ \\
\hline Median age (yrs) & 68 (range 35-87) & \\
\hline$\leq 65$ & 70 & 42.9 \\
\hline$>65$ & 93 & 57.1 \\
\hline \multicolumn{3}{|l|}{ ECOG Performance status } \\
\hline 0 & 118 & 69.8 \\
\hline 1 & 37 & 24.5 \\
\hline 2 & 8 & 5.8 \\
\hline ER positive/PR positive & 141 & 86.5 \\
\hline ER positive/PR negative & 22 & 13.5 \\
\hline Her 2 negative & 145 & 91.8 \\
\hline Her 2 positive & 13 & 8.2 \\
\hline \multicolumn{3}{|l|}{ Metastatic sites } \\
\hline Bone & 50 & 30.7 \\
\hline Node & 47 & 28.8 \\
\hline Visceral & 72 & 44.2 \\
\hline Brain & 3 & 1.8 \\
\hline Other & 13 & 8.0 \\
\hline \multicolumn{3}{|l|}{ Number of sites of disease } \\
\hline 1 & 78 & 47.9 \\
\hline$>1$ & 85 & 52.1 \\
\hline \multicolumn{3}{|l|}{ Previous endocrine therapy } \\
\hline Adjuvant & 120 & 73,6 \\
\hline Tamoxifen & 63 & 39.0 \\
\hline Aromatase inhibitors & 75 & 46.0 \\
\hline Advanced first line ET & 89 & 54.6 \\
\hline Tamoxifen & 11 & 6.7 \\
\hline Aromatase inhibitors & 78 & 41.7 \\
\hline \multicolumn{3}{|l|}{ Setting of Fulvestrant administration } \\
\hline $1^{\text {st }}$ line setting (naïve) & 9 & 6 \\
\hline Fulvestrant after adjuvant ET & 58 & 35 \\
\hline Fulvestrant after ET for advanced disease & 81 & 50 \\
\hline $1^{\text {st }}$ line maintenance after $\mathrm{CT}$ for advanced disease & 15 & 9 \\
\hline Endocrine sensitive (ES) & 90 & 55.2 \\
\hline
\end{tabular}

the present study confirm fulvestrant efficacy, with a CBR which fairly compares with data from randomized clinical trials. As expected, ES patients showed better outcome compared to non-ES patients, while patients with visceral disease had the worst outcome. Earlier use of fulvestrant was associated with better response. In addition, patients with an estrogen receptor percent expression higher than $50 \%$ seems to respond better than patients with lower percent expression. Within the highly-expressing subset of patients, the ability of Fulvestrant HD to exert ERdown regulation is mainly due to the blockade of of ERmediated transcription and acceleration of ER-degradation 


\section{Grade 1}

\begin{tabular}{lcc} 
& $\mathbf{n}$ & $\mathbf{\%}$ \\
\cline { 2 - 3 } Pain & 72 & 44.2 \\
Asthenia & 29 & 17,8 \\
Arthralgia & 24 & 14.7 \\
Headache & 15 & 9.2 \\
Nausea/vomiting & 4 & 7.5 \\
Hyperlipidemia & 4 & 2.5 \\
Flushes & 3 & 1,8 \\
Constipation & 1 & 0.6 \\
Diarrhea & 1 & 0.6 \\
\hline
\end{tabular}

A

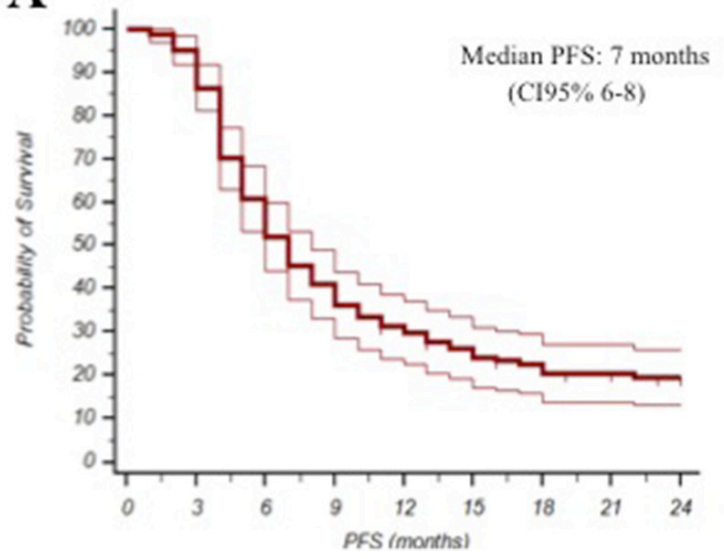

B

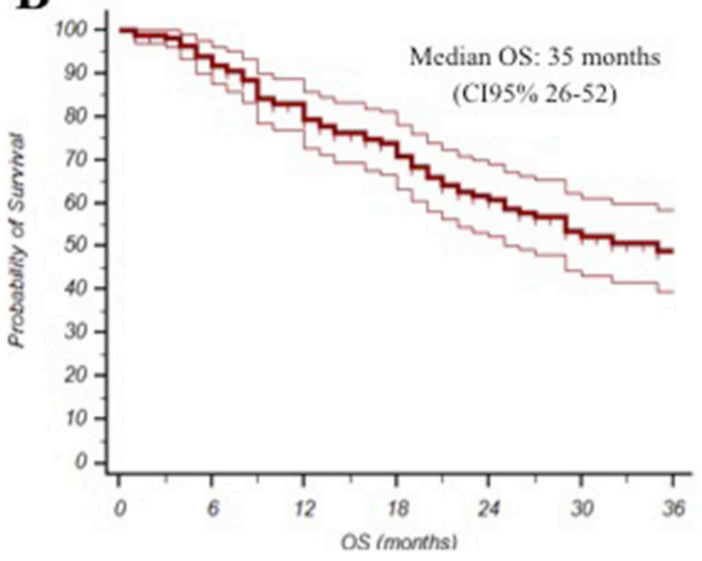

Figure 1: Kaplan-Meyer plot for Progression Free Survival (A) and Overall Survival (B).
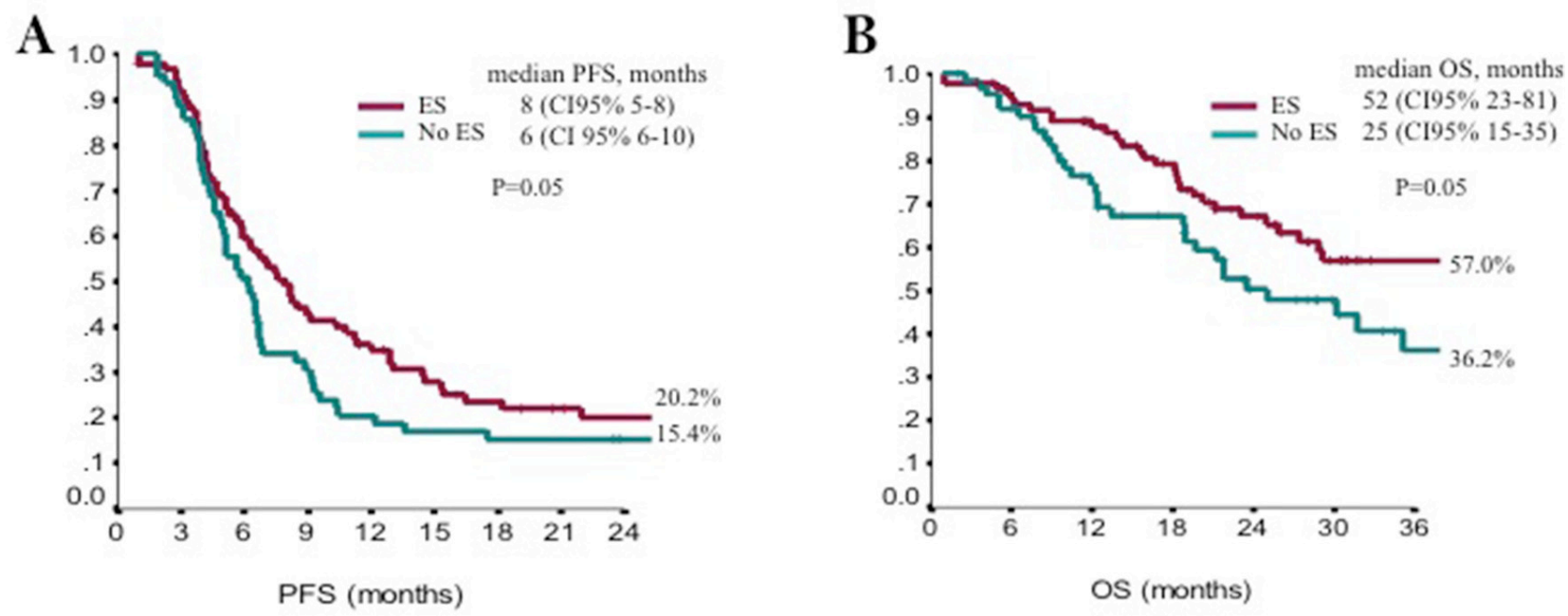

Figure 2: Kaplan-Meyer plot for Progression Free Survival (A) and Overall Survival (B) according to endocrine sensitivity (ES). 
Table 3: Multivariate regression analysis

\begin{tabular}{|c|c|c|c|}
\hline PFS & HR & IC95\% & $\mathbf{P}$ \\
\hline $\begin{array}{l}\text { Visceral } \\
\text { (yes vs no) }\end{array}$ & 1.52 & $1.06-2.18$ & 0.022 \\
\hline $\begin{array}{l}\text { Previous endocrine therapy } \\
(>1 \text { vs } 1)\end{array}$ & 1.88 & $1.28-2.76$ & 0.001 \\
\hline $\begin{array}{l}\text { Endocrine sensitivity } \\
\text { (no vs yes) }\end{array}$ & 1.66 & $1.14-2.43$ & 0.009 \\
\hline \multicolumn{4}{|l|}{ OS } \\
\hline $\begin{array}{l}\text { Number sites of disease } \\
(>1 \text { vs } 1)\end{array}$ & 2.29 & $1.37-3.85$ & 0.002 \\
\hline $\begin{array}{l}\text { Endocrine sensitivity } \\
\text { (no vs yes) }\end{array}$ & 1.61 & $0.98-2.64$ & 0.059 \\
\hline $\begin{array}{l}\text { Metastasis at diagnosis } \\
\text { (no vs yes) }\end{array}$ & 1.98 & $1.11-3.55$ & 0.021 \\
\hline CBR & OR & & \\
\hline $\begin{array}{l}\text { Estrogen receptor } \\
(>50 \% \text { vs }<50 \%)\end{array}$ & 3.49 & $1.30-9.38$ & 0.01 \\
\hline $\begin{array}{l}\text { Site of metastasis } \\
(1 \mathrm{vs}>1)\end{array}$ & 2.21 & $1.08-4.50$ & 0.03 \\
\hline $\begin{array}{l}\text { Previous ET for advanced disease } \\
\text { (no vs yes) }\end{array}$ & 2.24 & $1.1-4.58$ & 0.03 \\
\hline
\end{tabular}

through ubiquitin proteolysis [30]. This prospective trial has some limitations, it is a prospective evaluation of patients who were not selected upon strictly applied inclusion/exclusion criteria and treated as per clinical practice. This leads the way to a number of potential biases. Nonetheless, results from our analysis do not differ from those reported in the literature, thus confirming the effectiveness of this treatment even in unselected population outside of clinical trials. New treatments for the endocrine sensitive breast cancer setting are now under development. Ongoing trials are currently exploring the associations of fulvestrant or AIs with cyclin-dependent kinases 4 and 6. Results from the PALOMA-2, that compared treatment with palbociclib and letrozole with letrozole alone in the first-line setting for endocrine naïve patients, showed impressive improvement of median PFS for the palbociclib and letrozole association (24.8 months compared to 14.5 months of the letrozole group). However, data on OS are not available yet [31]. The PALOMA-3 trial compared palbociclib and fulvestrant with fulvestrant alone in pretreated patients. Median PFS for the experimental arm was 9.2 months compared to 3.8 months for the control group. Other cyclin-inhibitors are under investigation and the upcoming results will clarify the role of their association with the currently available endocrine therapies $[32,33,34]$. The addition of the CDK4/6 inhibitor ribociclib to letrozole showed a $44 \%$ improvement of the PFS of postmenopausal advanced breast cancer women treated in the first line setting [35]. Moreover it will be of interest the role of fulvestrant in estrogen receptor (ESR1) mutant breast cancers. Retrospective analyses of ESR1 status were performed in the SoFEA and PALOMA 3 trials. Patients with ESR 1 mutated tumors seemed to respond better to fulvestrant or fulvestrant plus palbociclib [36, 37]. The results obtained from the present analysis show that fulvestrant remain an optimal choice in first-line as well as in second line following prior hormone therapy. Fulvestrant $500 \mathrm{mg}$ has consistently showed to be a safe and active treatment and has confirmed its efficacy also in the daily clinical practice. Treatment was very well tolerated. A high estrogen receptor expression (above 50\%) seems to correlate to a higher CBR. Endocrine sensitivity surely has a major impact on treatment outcome and, as expected, patients who had received first-line ET for advanced disease prior to fulvestrant had worse outcome, including lower CBR. To our knowledge, this study represents the first prospective trial, carried out in the clinical practice setting to confirm the efficacy and safety of fulvestrant HD therapy. In this view, our results may add useful information to the management of endocrine sensitive breast cancer patients. From a cost-effective point of view, fulvestrant HD was compared to the $250 \mathrm{mg}$ dose and to the generic nonsteroidal aromatase inhibitors 
(anastrozole and letrozole); an increase of costs were observed and this can be a critical issue if we consider the financial sustainability of the national health system in some disadvantaged regions. However, certain subgroups of patients may benefit from fulvestrant as a treatment option [38, 39]. The recent results from the FALCON trial confirmed [27] the efficacy of fulvestrant in the first line treatment and added a new opportunity to the firstline options available for treatment of naïve endocrine sensitive breast cancer patients.

\section{MATERIALS AND METHODS}

Eligible patients were women with advanced endocrine sensitive breast cancer, suitable to receive endocrine therapy with fulvestrant. Patients were included if having experienced relapse while on or after the completion of adjuvant endocrine therapy, or presenting with de novo advanced disease, or if previously treated with either an antiestrogen or an aromatase inhibitor in first-line. Patients who received fulvestrant as maintenance therapy after chemotherapy for advanced disease were also included. Endocrine sensitive patients were defined as follows: patients who progressed after a least 24 months from the completion of adjuvant endocrine therapy (ET) or after at least than 24 weeks of endocrine treatment for advanced disease. The lack of endocrine sensitivity was defined as disease progression while on or within two years from the completion of adjuvant ET or patients who progressed within the first 24 weeks of endocrine treatment for advanced disease. Main exclusion criteria were: extensive visceral involvement, visceral crisis, central nervous system metastases not adequately controlled, Eastern Cooperative Oncology Group Performance Status (ECOG PS) $>2$. Fulvestrant $500 \mathrm{mg}$ was given as two 5-mL intramuscular (IM) injections, on days 0,14 , and 28 for the first months and every 28 days thereafter until progressive disease, unacceptable toxicity or withdrawal of informed consent. Response was evaluated as per RECIST 1.1 criteria every 12 weeks from baseline until progressive disease. Adverse events were monitored monthly and classified with the National Cancer Institute Common Toxicity Criteria v.4.0 (NCICTC 4.0). The primary endpoint was clinical benefit rate (CBR) defined as the sum of complete responses (CR), partial responses (PR) and stable disease (SD) for at least 24 weeks. Secondary endpoints were progression free survival (PFS) and overall survival (OS).

\section{Statistical analysis}

Descriptive statistics were used to summarize pertinent study information. The Chi-Square or Fisher Exact tests were used to estimate associations between categorical variables. Odds Ratio (OR) and the 95\% confidence intervals $(95 \% \mathrm{CI})$ were estimated for each variable of interest in univariate regression models. The variables tested by univariate analysis were age ( $<65$ vs $\geq 65$ years), performance status ( 0 -1 vs 2 ), expression of estrogen and progesteron receptor ( $\geq 50 \%$ vs $<50 \%$ ), Her-2 positivity (score $3+$ vs others), Ki-67 value ( $<20 \%$ vs $>20 \%$, sites of disease (visceral vs other), metastasis at diagnosis (yes vs no), previous endocrine therapy (aromatase inhibitors vs antiestrogen), number of previous line of treatment (first-line vs $\geq 2$ ), endocrine sensitivity (yes vs no). A multivariate logistic regression model was developed using stepwise regression (forward selection, enter limit and remove limit, $\mathrm{p}=0.10$ and $\mathrm{p}=0.15$, respectively) to identify independent predictors of CBR. Survival estimates were computed and compared by the Kaplan-Meier product-limit and log-rank test. The Hazard Ratio (HR) and 95\% confidence intervals (95\% CI) were estimated by using Cox univariate models. The included variables for PFS and OS were age ( $<65$ vs $\geq 65$ years), performance status (0-1 vs 2), expression of estrogen and progesteron receptor ( $\geq 50 \%$ vs $<50 \%$ ), Her- 2 positivity (score $3+$ vs others), ki 67 percent expression $(<20 \%$ vs $>20 \%$, sites of disease (visceral vs other), metastasis at diagnosis (yes vs no), previous endocrine therapy (aromatase inhibitors vs antiestrogen), number of previous line of treatment (first-line vs $\geq 2$ ), endocrine sensitivity (yes vs no). A multivariate Cox proportional hazard model including clinical-pathological features and details on treatment was developed using stepwise regression (forward selection, enter limit and remove limit, $p=0.10$ and $\mathrm{p}=0.15$, respectively), to identify independent predictors of PFS and OS. The SPSS software (SPSS version 21.0, SPSS Inc., Chicago, Illinois, USA) was used for all statistical evaluations. The sample size was calculated based on an estimated CBR of $45 \%$ observed in our previous fulvestrant trial [19]. Effectiveness measures included PFS duration, defined as the time elapsed between the date at fulvestrant start and disease progression [PD] or death, and OS duration, defined as the time window between the begin of fulvestrant and death or censoring. Disease staging was performed as per clinical practice with physical examination and diagnostic techniques for radiologic imaging. Fulvestrant treatment was continued until disease progression, unacceptable toxicities, and patient consent withdrawal. Subsequent lines of therapy were at the discretion of the investigators. The ethics committee of each participating institution approved the protocol. Patients were treated according to the Helsinki declaration and a written informed consent was secured from each patient before study entrance.

\section{ACKNOWLEDGMENTS}

LM, PV, TM, CN, conceived of the study, and participated in its design and coordination and helped draft the manuscript. IS participated in the design of the study and performed the statistical analysis. All authors read and approved the final manuscript. BM revised the English. 


\section{CONFLICTS OF INTEREST}

The authors declare no conflicts of interest.

\section{GRANT SUPPORT}

Not Applicable. This study represents spontaneous work from the institutions involved.

\section{REFERENCES}

1. Stat Fact Sheets SE. Female Breast Cancer. seer.cancer.gov/ statfacts/html/Breast [May 26, 2016].

2. Jatoi I, Chen BE, Anderson WF, Rosenberg PS. Breast cancer mortality trends in the United States according to estrogen receptor status and age at diagnosis. J Clin Oncol. 2007; 25:1683-90.

3. Brewster AM, Hortobagyi GN, Broglio KR, Kau SW, Santa-Maria CA, Arun B, Buzdar AU, Booser DJ, Valero V, Bondy M, Esteva FJ. Residual risk of breast cancer recurrence 5 years after adjuvant therapy. J Natl Cancer Inst. 2008; 20:1179-83.

4. NCCN - Clinical practice guidelines in oncology, breast cancer V2.2016.

5. Bonneterre J, Buzdar A, Nabholtz JM, Robertson JF, Thürlimann B, von Euler M, Sahmoud T, Webster A, Steinberg M, Arimidex Writing Committee, Investigators Committee Members. Anastrozole is superior to tamoxifen as first-line therapy in hormone receptor positive advanced breast carcinoma. Cancer. 2001; 92:2247-58.

6. Mouridsen H, Gershanovich M, Sun Y, Pérez-Carrión R, Boni C, Monnier A, Apffelstaedt J, Smith R, Sleeboom HP, Jänicke F, Pluzanska A, Dank M, Becquart D, et al. Superior efficacy of letrozole versus tamoxifen as first-line therapy for postmenopausal women with advanced breast cancer: results of a phase III study of the International Letrozole Breast Cancer Group. J Clin Oncol. 2001; 19:2596-606.

7. Paridaens R, Dirix L, Lohrisch C, Beex L, Nooij M, Cameron D, Biganzoli L, Cufer T, Duchateau L, Hamilton A, Lobelle JP, Piccart M, and European Organization for the Research and Treatment of Cancer (EORTC)Investigational Drug Branch for Breast Cancer (IDBBC). Mature results of a randomized phase II multicenter study of exemestane versus tamoxifen as first-line hormone therapy for postmenopausal women with metastatic breast cancer. Ann Oncol. 2003; 14:1391-98.

8. Wakeling AE. Similarities and distinctions in the mode of action of different classes of antioestrogens. Endocr Relat Cancer. 2000; 7:17-28.

9. Osborne CK, Wakeling A, Nicholson RI. Fulvestrant: an oestrogen receptor antagonist with a novel mechanism of action. Br J Cancer. 2004; 90:S2-6.

10. Howell A, Robertson JF, Quaresma Albano J, Aschermannova A, Mauriac L, Kleeberg UR, Vergote I,
Erikstein B, Webster A, Morris C. Fulvestrant, formerly ICI 182,780 , is as effective as anastrozole in postmenopausal women with advanced breast cancer progressing after prior endocrine treatment. J Clin Oncol. 2002; 20:3396-403.

11. Osborne CK, Pippen J, Jones SE, Parker LM, Ellis M, Come S, Gertler SZ, May JT, Burton G, Dimery I, Webster A, Morris C, Elledge R, Buzdar A. Double-blind, randomized trial comparing the efficacy and tolerability of fulvestrant versus anastrozole in postmenopausal women with advanced breast cancer progressing on prior endocrine therapy: results of a North American trial. J Clin Oncol. 2002; 20:3386-95.

12. Robertson JF, Osborne CK, Howell A, Jones SE, Mauriac L, Ellis M, Kleeberg UR, Come SE, Vergote I, Gertler S, Buzdar A, Webster A, Morris C. Fulvestrant versus anastrozole for the treatment of advanced breast carcinoma in postmenopausal women: a prospective combined analysis of two multicenter trials. Cancer. 2003; 98:229-38.

13. Howell A, Pippen J, Elledge RM, Mauriac L, Vergote I, Jones SE, Come SE, Osborne CK, Robertson JF. Fulvestrant versus anastrozole for the treatment of advanced breast carcinoma: a prospectively planned combined survival analysis of two multicenter trials. Cancer. 2005; 104:236-39.

14. Ingle JN, Suman VJ, Rowland KM, Mirchandani D, Bernath AM, Camoriano JK, Fishkin PA, Nikcevich DA, Perez EA, and North Central Cancer Treatment Group Trial N0032. Fulvestrant in women with advanced breast cancer after progression on prior aromatase inhibitor therapy: North Central Cancer Treatment Group Trial N0032. J Clin Oncol. 2006; 24:1052-56.

15. Chia S, Gradishar W, Mauriac L, Bines J, Amant F, Federico M, Fein L, Romieu G, Buzdar A, Robertson JF, Brufsky A, Possinger K, Rennie P, et al. Double-blind, randomized placebo controlled trial of fulvestrant compared with exemestane after prior nonsteroidal aromatase inhibitor therapy in postmenopausal women with hormone receptorpositive, advanced breast cancer: results from EFECT. J Clin Oncol. 2008; 26:1664-70.

16. DeFriend DJ, Howell A, Nicholson RI, Anderson E, Dowsett M, Mansel RE, Blamey RW, Bundred NJ, Robertson JF, Saunders C, Baum M, Walton P, Sutcliffe F, Wakeling AE. Investigation of a new pure antiestrogen (ICI 182780 ) in women with primary breast cancer. Cancer Res. 1994; 54:408-14.

17. Robertson JF, Nicholson RI, Bundred NJ, Anderson E, Rayter Z, Dowsett M, Fox JN, Gee JM, Webster A, Wakeling AE, Morris C, Dixon M. Comparison of the short-term biological effects of 7alpha-[9-(4,4,5,5,5-pentafluoropentylsulfinyl)nonyl] estra-1,3,5, (10)-triene-3,17beta-diol (Faslodex) versus tamoxifen in postmenopausal women with primary breast cancer. Cancer Res. 2001; 61:6739-46.

18. Kuter I, Gee JM, Hegg R, Singer CF, Badwe RA, Lowe ES, Emeribe UA, Anderson E, Sapunar F, Finlay P, Nicholson RI, Bines J, Harbeck N. Dose-dependent change 
in biomarkers during neoadjuvant endocrine therapy with fulvestrant: results from NEWEST, a randomized Phase II study. Breast Cancer Res Treat. 2012; 133:237-46.

19. Di Leo A, Jerusalem G, Petruzelka L, Torres R, Bondarenko IN, Khasanov R, Verhoeven D, Pedrini JL, Smirnova I, Lichinitser MR, Pendergrass K, Garnett S, Lindemann JP, et al. Results of the CONFIRM phase III trial comparing fulvestrant $250 \mathrm{mg}$ with fulvestrant $500 \mathrm{mg}$ in postmenopausal women with estrogen receptor-positive advanced breast cancer. J Clin Oncol. 2010; 28:4594-600.

20. Di Leo A, Jerusalem G, Petruzelka L, Torres R, Bondarenko IN, Khasanov R, Verhoeven D, Pedrini JL, Smirnova I, Lichinitser MR, Pendergrass K, Malorni L, Garnett S, et al. Final overall survival: fulvestrant $500 \mathrm{mg}$ vs $250 \mathrm{mg}$ in the randomized CONFIRM trial. J Natl Cancer Inst. 2014; 106:djt337.

21. Ohno S, Rai Y, Iwata H, Yamamoto N, Yoshida M, Iwase H, Masuda N, Nakamura S, Taniguchi H, Kamigaki S, Noguchi $\mathrm{S}$. Three dose regimens of fulvestrant in postmenopausal Japanese women with advanced breast cancer: results from a double-blind, phase II comparative study (FINDER1). Ann Oncol. 2010; 21:2342-47.

22. Pritchard KI, Rolski J, Papai Z, Mauriac L, Cardoso F, Chang J, Panasci L, Ianuli C, Kahan Z, Fukase K, Lindemann JP, Macpherson MP, Neven P. Results of a phase II study comparing three dosing regimens of fulvestrant in postmenopausal women with advanced breast cancer (FINDER2). Breast Cancer Res Treat. 2010; 123:453-61.

23. Cope S, Ouwens MJ, Jansen JP, Schmid P. Progression-free survival with fulvestrant $500 \mathrm{mg}$ and alternative endocrine therapies as second-line treatment for advanced breast cancer: a network meta-analysis with parametric survival models. Value Health. 2013; 16:403-17.

24. Zhang Q, Shao Z, Shen K, Li L, Feng J, Tong Z, Gu K, Wang X, Xu B, Sun G, Chen H, Rukazenkov Y, Jiang Z. Fulvestrant $500 \mathrm{mg}$ vs $250 \mathrm{mg}$ in postmenopausal women with estrogen receptor-positive advanced breast cancer: a randomized, double-blind registrational trial in China. Oncotarget. 2016; 7:57301-09. https://doi.org/10.18632/ oncotarget.10254.

25. Robertson JF, Llombart-Cussac A, Rolski J, Feltl D, Dewar J, Macpherson E, Lindemann J, Ellis MJ. Activity of fulvestrant $500 \mathrm{mg}$ versus anastrozole $1 \mathrm{mg}$ as firstline treatment for advanced breast cancer: results from the FIRST study. J Clin Oncol. 2009; 27:4530-35.

26. Ellis MJ, Llombart-Cussac A, Feltl D, Dewar JA, Jasiówka M, Hewson N, Rukazenkov Y, Robertson JF. Fulvestrant $500 \mathrm{mg}$ Versus Anastrozole $1 \mathrm{mg}$ for the First-Line Treatment of Advanced Breast Cancer: Overall Survival Analysis From the Phase II FIRST Study. J Clin Oncol. 2015; 33:3781-87.

27. Ellis MJ, Bondarenko I, Trishkina E, Dvorkin M, Panasci LA, Manikhas A, Shparyk Y, Cardona-Huerta S, Cheung KL, Philco-Salas MJ, Ruiz-Borrego M, Shao ZS, Noguchi $\mathrm{S}$, et al. FALCON: A phase III randomised trial of fulvestrant $500 \mathrm{mg}$ vs. anastrozole for hormone receptorpositive advanced breast cancer. Ann Oncol. 2016; 27.

28. Telford C, Jones N, Livings C, Batson S. Network MetaAnalysis Comparing Overall Survival for Fulvestrant $500 \mathrm{mg}$ Versus Alternative Therapies for Treatment of Postmenopausal, Estrogen Receptor-Positive Advanced Breast Cancer Following Failure on Prior Endocrine Therapy. Clin Breast Cancer. 2016; 16:188-95.

29. Ishida N, Araki K, Sakai T, Kobayashi K, Kobayashi T, Fukada I, Hosoda M, Yamamoto M, Ichinokawa K, Takahashi S, Iwase T, Ito Y, Yamashita H. Fulvestrant $500 \mathrm{mg}$ in postmenopausal patients with metastatic breast cancer: the initial clinical experience. Breast Cancer. 2016; 23:617-23.

30. Wakeling AE, Dukes M, Bowler J. A potent specific pure antiestrogen with clinical potential. Cancer Res. 1991; 51:3867-73.

31. Finn RS, Martin M, Rugo HS, Jones SE, Im SA, Gelmon KA, Harbeck N, Lipatov ON, Walshe JM, Moulder SL, Gauthier ER, Lu D, Randolph S, et al. PALOMA-2: Primary results from a phase III trial of palbociclib $(\mathrm{P})$ with letrozole (L) compared with letrozole alone in postmenopausal women with ER+/HER2 - advanced breast cancer (ABC). J Clin Oncol. 2016; 34: 507.

32. Turner NC, Ro J, André F, Loi S, Verma S, Iwata H, Harbeck N, Loibl S, Huang Bartlett C, Zhang K, Giorgetti C, Randolph S, Koehler M, Cristofanilli M, and PALOMA3 Study Group. Palbociclib in hormone-receptorpositive advanced breast cancer. N Engl J Med. 2015; 373:209-19.

33. Vidula N, Rugo HS. Cyclin-dependent kinase $4 / 6$ inhibitors for the treatment of breast cancer: A review of preclinical and clinical data. Clin Breast Cancer. 2016; 16:8-17.

34. Barroso-Sousa R, Shapiro GI, Tolaney SM. Clinical Development of the CDK4/6 Inhibitors Ribociclib and Abemaciclib in Breast Cancer. Breast Care (Basel). 2016; 11:167-73.

35. Hortobagyi GN, Stemmer SM, Burris HA, Yap YS, Sonke GS, Paluch-Shimon S, Campone M, Blackwell K, André F, Winer EP, Janni W, Verma S, Conte P, et al. Firstline ribociclib + letrozole for postmenopausal women with hormone receptor-positive (HR+), HER2-negative (HER2-), advanced breast cancer (ABC). Ann Oncol. 2016; 27:1-36.

36. Fribbens C, O'Leary B, Kilburn L, Hrebien S, GarciaMurillas I, Beaney M, Cristofanilli M, Andre F, Loi S, Loibl $\mathrm{S}$, Jiang J, Bartlett $\mathrm{CH}$, Koehler M, et al. Plasma ESR1 mutations and the treatment of estrogen receptor-positive advanced breast cancer. J Clin Oncol. 2016; 34:2961-68.

37. Johnston SR, Kilburn LS, Ellis P, Dodwell D, Cameron D, Hayward L, Im YH, Braybrooke JP, Brunt AM, Cheung KL, Jyothirmayi R, Robinson A, Wardley AM, et al, and SoFEA investigators. Fulvestrant plus anastrozole or placebo versus exemestane alone after progression on non-steroidal aromatase inhibitors in postmenopausal patients with 
hormone-receptor-positive locally advanced or metastatic breast cancer (SoFEA): a composite, multicentre, phase 3 randomised trial. Lancet Oncol. 2013; 14:989-98.

38. Newman MJ, Jones LT, Kraft JM, Lee AR, Lech GM, Farrell NM, Phantumvanit V, Edwards RA. Cost-effectiveness of fulvestrant $250 \mathrm{mg}$ versus $500 \mathrm{mg}$ in postmenopausal women with estrogen receptor-positive metastatic breast cancer and disease progression after antiestrogen therapy. J Oncol Pharm Pract. 2012; 18:394-401.

39. Das R, Cope S, Ouwens M, Turner P, Howlett M. Economic evaluation of fulvestrant $500 \mathrm{mg}$ versus generic nonsteroidal aromatase inhibitors in patients with advanced breast cancer in the United Kingdom. Clin Ther. 2013; 35:246-260.e5. 